\title{
Synthesis of Carbon Nanotubes from Byproducts of Oil Refiner
}

\author{
S. H. Abdullayeva ${ }^{1,2}$, N. N. Musayeva1,2*, R. B. Jabbarovi,2, T. Matsuda ${ }^{3}$ \\ ${ }^{1}$ G. M. Abdullayev Institute of Physics, Azerbaijan NAS, Baku, Azerbaijan \\ ${ }^{2}$ Research \& Development Center for Hi-Technologies, MCIT, Baku, Azerbaijan \\ ${ }^{3}$ Osaka University, Osaka, Japan \\ Email: ${ }^{*}$ nmusayeva@physics.ab.az
}

Received 6 May 2014; revised 17 June 2014; accepted 3 July 2014

Copyright (C) 2014 by authors and Scientific Research Publishing Inc.

This work is licensed under the Creative Commons Attribution International License (CC BY). http://creativecommons.org/licenses/by/4.0/

(c) (i) Open Access

\begin{abstract}
Carbon nanotubes have been synthesized by using petroleum coke (PC) as carbon source. Different position of the $P C$ in the reactor chamber and some other reaction parameters is strongly influenced to quantity of the obtained CNTs and their characteristics such as crystallinity, diameter (number of shels), and etc., which is analysed by scanning and tranmission electron microscopes (SEM and TEM). The thickness of the Fe catalyst deposited on $\mathrm{Si}$ and $\mathrm{SiO}_{2}$ substrates supported improves the quality, quantity and uniformity of CNTs. Wet-coated thin films of $\mathrm{FeCl}_{2}$ work well as catalyst, which can be profitable for mass production of CNTs.
\end{abstract}

\section{Keywords}

Carbon Nanotubes, Petroleum Coke, Catalyst, Byproduct

\section{Introduction}

Carbon nanotube, which is one of the allotrope of carbon, has been attracted worldwide after their discovery in 1991 by Iijma [1]. Carbon nanotubes have distinguishing properties like mechanical, thermal, electrical, etc. which make them useful in many fields of our daily lives.

CNTs can be classified into two main categories: single-walled carbon nanotubes (SWNTs) and multi-walled carbon nanotubes (MWNTs) [2]. It is of great interest to understand what factors control the nanotube sizes, number of shells, the helicity and the structure during synthesis; this is due to the fact that different atomic structure of the tubes may result in great changes in their properties [3]-[5].

In general, CNTs are synthesized by arc discharge [6], laser ablation [7], chemical vapor deposition (CVD) [8]

Corresponding author.

How to cite this paper: Abdullayeva, S.H., Musayeva, N.N., Jabbarov, R.B. and Matsuda, T. (2014) Synthesis of Carbon Nanotubes from byproducts of Oil Refiner. World Journal of Condensed Matter Physics, 4, 93-100.

http://dx.doi.org/10.4236/wjcmp.2014.43014 
and spray pyrolysis [9].

Although first two methods from above mentioned can produce high quality SWNTs, the available quantity from both arc discharge and laser ablation is limited.

CVD is more promising and cheaper method for synthesizing CNTs, for large scale production. Because good quality SWCNTs are quite expensive due to synthesis technologies. The other problem is to choose the suitable eco-friendly carbon source for synthesizing high quality CNTs with good parameters and low cost.

Therefore many authors used different carbon sources, like cyclohexane, acetonitrile [10], benzene [11] [12], xylene [13], alcohols [14] et al. for synthesizing of both single and multiwall carbon nanotubes by CVD method.

In this work, we demonstrate CNTs, synthesized by using byproduct of Caspian oil refiner.

Caspian oil is one of the high quality and light oil in the world. Oil in the Caspian has a long history—indeed it is one of the earliest oil production regions in the world, with Baku a major oil center in the second half of the 19th century and beyond. This Caspian Sea oil utilize as gasoline, jet fuel, LPG, fuel oil, asphalt after refining.

We had an idea to use byproduct-Petroleum Coke (PC) of oil refiner as carbon source for synthesizing of CNTs. The refining process diagram is shown in Figure 1.

To have knowledge about chemical contents of PC was carried out gas chromatographic and Fluorescent X-ray analysis, which results are shown in Figure 2.

We observed many aromatic hydrocarbons included in PC and impurities of oil are $\mathrm{Cl}, \mathrm{Al}$ and $\mathrm{S}$ elements.

\section{Experimental Results and Discussion}

Very thin Fe film has been deposited on $\mathrm{Si}$ and $\mathrm{SiO}_{2}$ substrates by $\mathrm{RF}$ sputtering technique. Fe small particles on the substrate used as catalyst for CNTs growth by gasification of PC-natural carbon source. Schematic illustration of growth process is shown in Figure 3.

The vapor in the reactor is transported in 2 steps:

1) He gas $185 \mathrm{sccm}$;

2) He $105 \mathrm{sccm}+\mathrm{H}_{2} 80 \mathrm{sccm}$.

Synthesized CNTs have been analyzed by Scanning Electron Microscope (SEM) HITACHI S-4500 and Transmission Electron Microscope (TEM) JEOL SE-2500.

It is observed that the $700^{\circ} \mathrm{C}$ is optimal temperature to grow CNTs by our synthesis method.

There are also some cases, which can optimize the growth process.

\section{1. $\mathrm{H}_{2}$ Is Key}

In first, experiments we used only pure He (185 sccm) gas as a transporter. In this case is grown very little quantity of carbon nanotubes on $\mathrm{Fe} / \mathrm{SiO}_{2}$ substrate, as it is seen from SEM observations (Figure 4(a)) TEM observation show that the grown CNTs in this condition are bamboo like (Figure 4(b)).

In the next experiments, we used $\mathrm{He} 105 \mathrm{sccm}+\mathrm{H}_{2} 80 \mathrm{sccm}$, and situation is changed, we obtained very much quantity CNTs on $\mathrm{Fe} / \mathrm{SiO}_{2}$ substrate in the same condition. And synthesized CNTs are more straight (Figure 5(a) and Figure 5(b)).

In fact that the following changes are expected when $\mathrm{H}_{2}$ presence in the reactor chamber:

- Enhance the dissociation of higher order of hydrocarbon molecules.

- Remove carbon atoms weakly bonded on the surface of CNTs.

- Prevent the deactivation of the catalyst.

The role of hydrogen in chemical vapor decomposition (CVD) of $\mathrm{C}_{2} \mathrm{H}_{4}$ for growth of carbon nanotubes (CNTs) was investigated by several authors, which reported that presence and quantity of hydrogen significantly influence to the structure of the grown CNTs (size, structure, morphology, or areal nanotube density) [15]-[22], while there is also probability that hydrogen etches away any amorphous carbon that may deposit on the catalyst and block the nanotube growth [23].

However, mechanism of such effects needs to be explained.

\subsection{Heating Procedure of Cokes}

The experiments show that the geometrical position of coke-as carbon source greatly influences to parameters of obtained CNTs. We have chosen three different positions for coke during the growth process: outside of the furnace; at edge of the furnace; inside of the furnace. All the positions have been shown in Figure 6. 


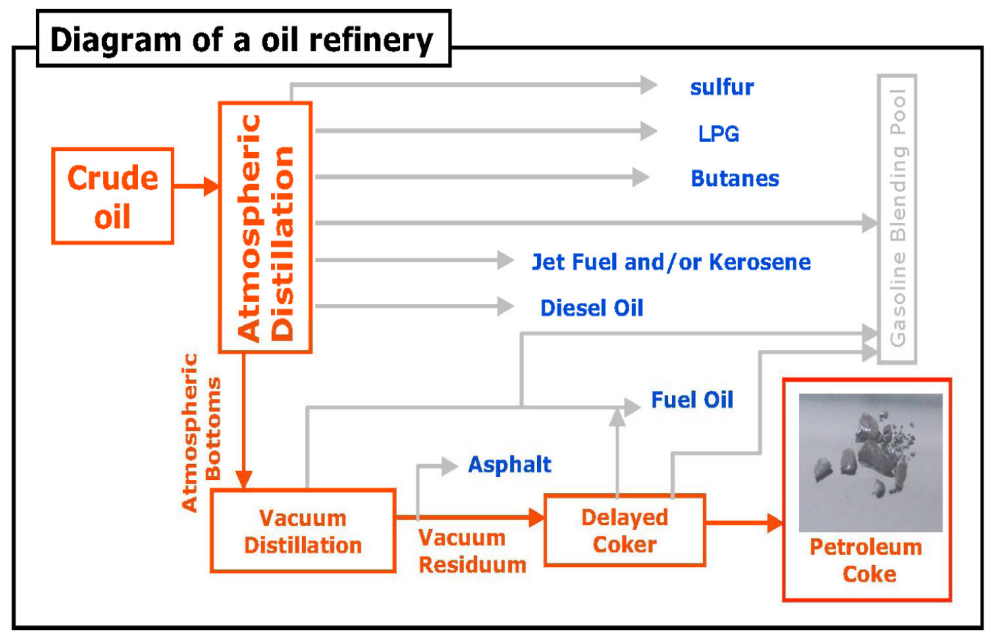

Figure 1. Oil refining process.

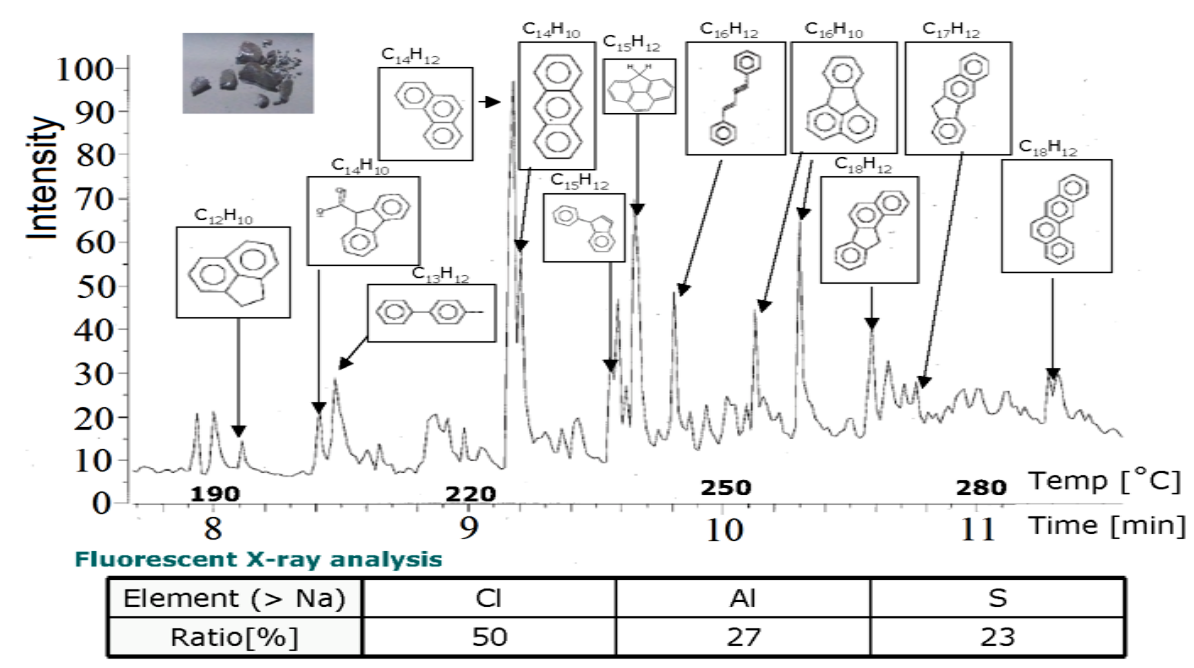

Figure 2. Gas chromatographic and Fluorescent X-ray analysis of the PC.

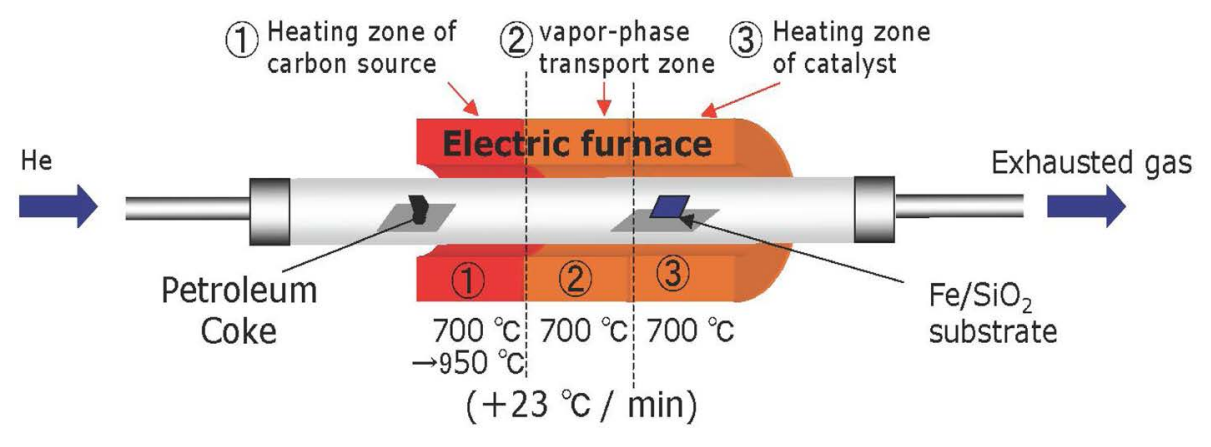

Figure 3. Schematic illustration of CNT growth process.

In the first position, coke is not heated for a long time, while inside it evaporates very quickly at high temperatures. Figure 7 shows SEM results of all cases. It is observed that, better result is obtained when coke is in edge of the furnace.

This phenomenon can be explained schematically with the diagrams (Figure 8). In first case excess carbon 

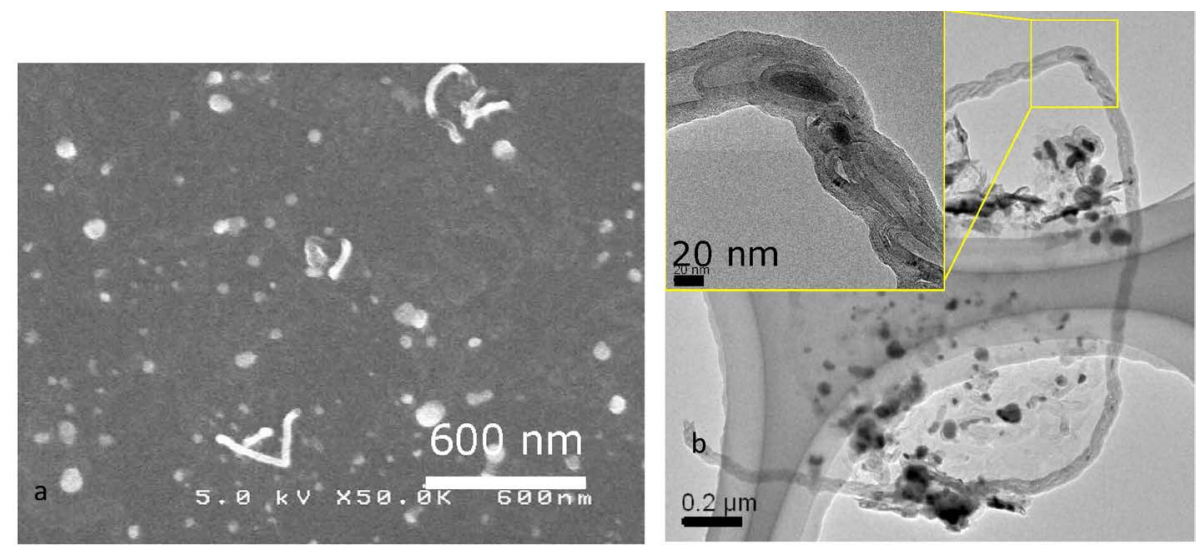

Figure 4. Gasification process under pure He (185 sccm); (a) SEM observations; (b) TEM observations.
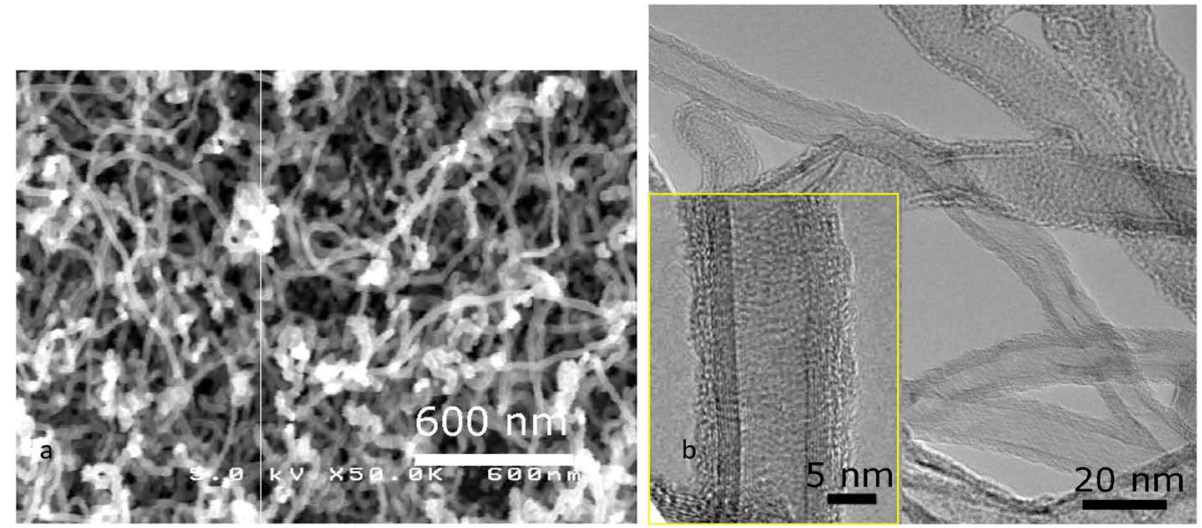

Figure 5. Gasification process under He $105 \mathrm{sccm}+\mathrm{H}_{2} 80 \mathrm{sccm}$; (a) SEM observations; (b) TEM observations.

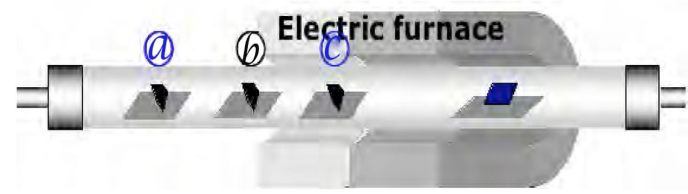

Figure 6. PC positions in the reactor.
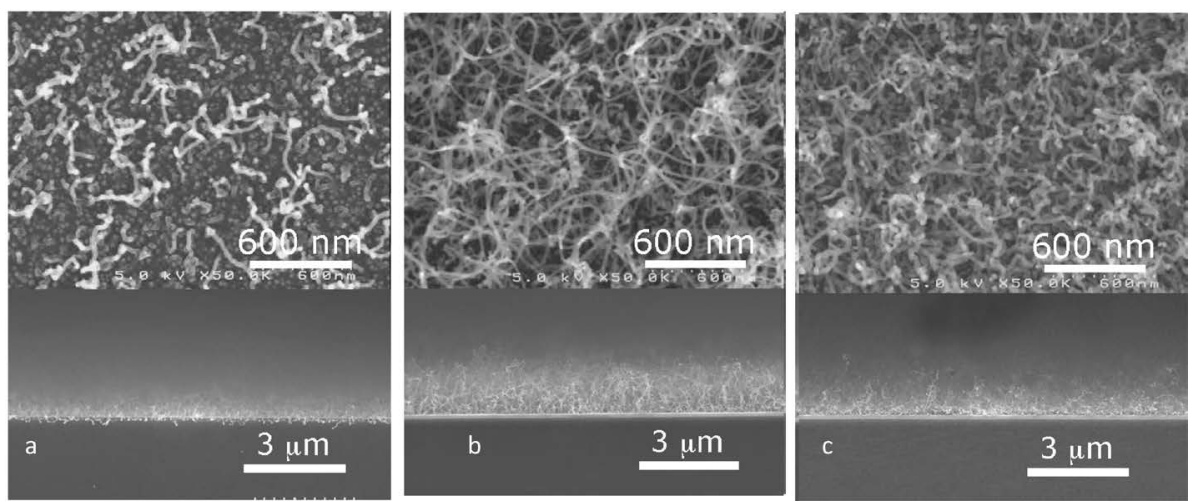

Figure 7. SEM observations of CNTs grown in cases PC is (a) outside of the furnace; (b) at edge of the furnace; (c) inside of the furnace. 


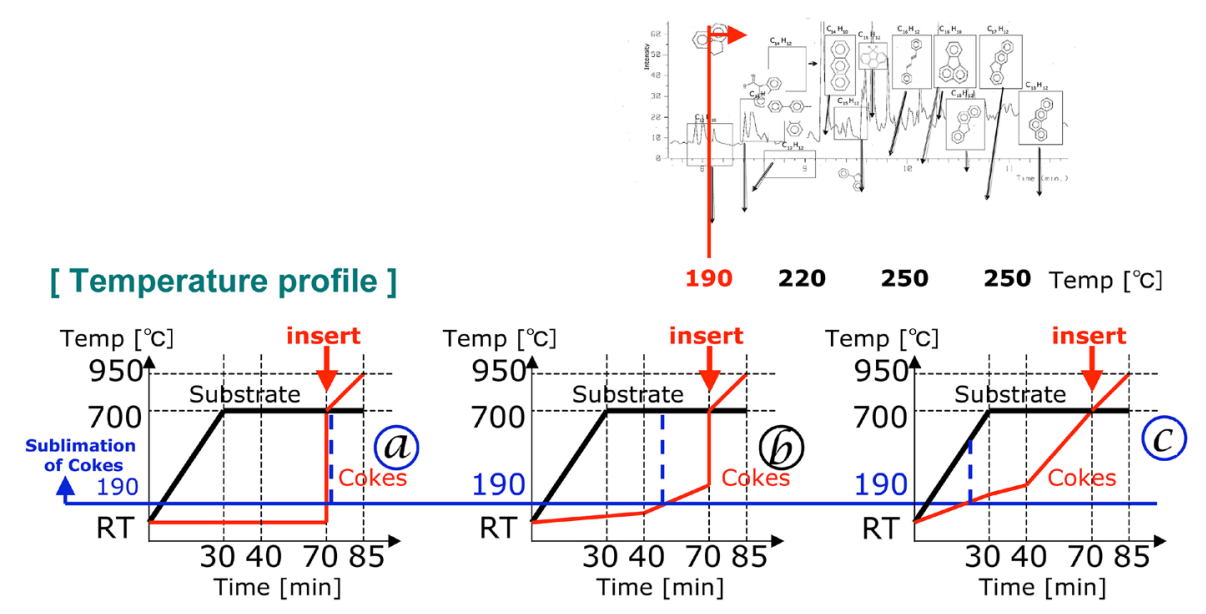

Figure 8. Schematic illustration of the processes in the reactor depending of the PC position.

was supplied in a short period and worked to deactivate the catalyst. When the coke is in edge of the furnace the moderate carbon was supplied after the substrate reached $700^{\circ} \mathrm{C}$. The diagram shows that the carbon was supplied before the catalyst was activated in the case of coke was inside of furnace.

\subsection{Role and Thickness Dependence of the Catalyst}

The catalyst (in this case a metal) is involved to control the kinetics of reactions such as decomposition of the precursor. It also acts as a geometric confinement for the forming CNT-structure. The catalyst can be located on a substrate or is delivered via the gas phase [24]-[26].

The correlation between prepatterned catalyst film thickness and carbon nanotube (CNT) growth by selective area Chemical Vapor Deposition (CVD) was studied using Fe, Co and Ni as catalysts [27] [28].

But the specific role of the catalyst in the nanotube growth process is not clear. Several growth mechanisms have been proposed, among them those where growth is expected to take place at "base" [29] and "tip" [30] locations with respect to the nanotube, have received partial evidences from experimental and theoretical studies. The main difference between them is given by the behavior of the C-metal nanoparticle during the growth process.

In this work, very thin Fe thin films were deposited on Si substrate by sputtering. Experiments show that when Fe layer thickness less than $1 \mathrm{~nm}$, smallest and less quantity CNTs are grown on the substrate. Better result obtained when Fe thickness are between 1 - 2 nm (Figure 9).

In this study, we used powders (control experiment) and wet coated $0.01 \% 40 \mu \mathrm{l}$ (liquid) $\mathrm{FeCl}_{2}$ as the catalyst to grow CNTs on quartz substrates. Both substrates putted in hot zone of the quarts reactor and growth temperature was $820^{\circ} \mathrm{C}$. SEM shows top views of the samples (Figure 10). Thin and spinnable CNTs are grown on thin coated $\mathrm{FeCl}_{2}$, while CNTs grown on $\mathrm{FeCl}_{2}$ powder are thicker and longer.

This unique method does not require the thin film deposition step, which shortens the time used for each batch of CNT growth [31]. The simplicity of this method allows an easy scale-up for mass production of CNTs with a low cost.

\section{Conclusions}

In this work, we have explored the condition for growing CNTs from petroleum cokes.

We have concluded that, the addition of $\mathrm{H}_{2}$ in the carrier gas is a key factor to grow high quantity and more strength CNTs.

Possible mechanism is to enhance the dissociation of higher order of hydrocarbon, remove carbon atoms weakly bonded on the surface of CNTs, and prevent the deactivation of the catalyst.

The control of the amount of hydrocarbon molecules from cokes is also a key factor. It is also important not to supply hydrocarbon molecules before the catalyst is activated.

Wet-coated thin films of $\mathrm{FeCl}_{2}$ work well as catalyst in the CNT growth process. This process is simplicity 

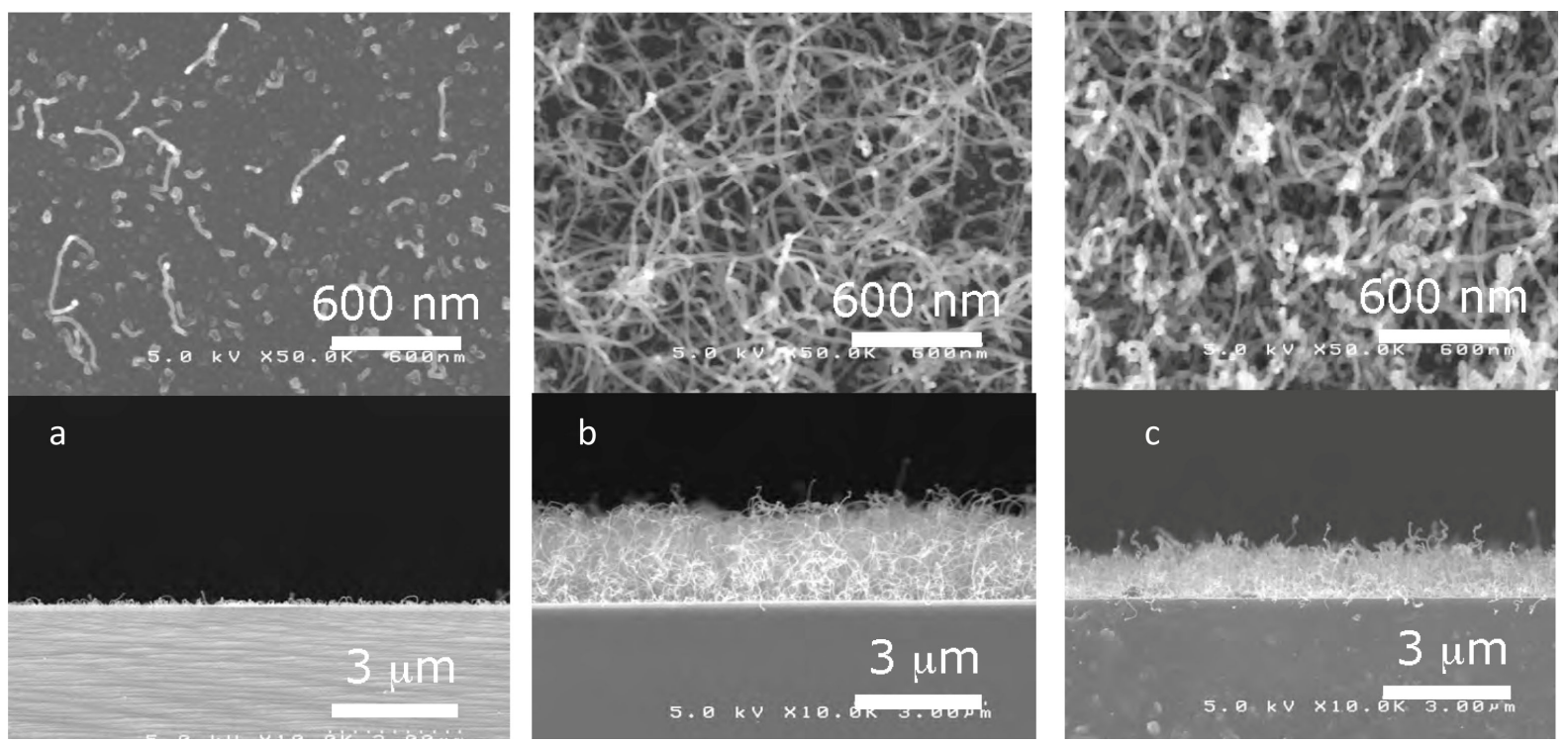

Figure 9. SEM observations of CNTs grown on: (a) $0.5 \mathrm{~nm} \mathrm{Fe}$; (b) $1.0 \mathrm{~nm}$; (c) $4 \mathrm{~nm}$ Fe thin films.
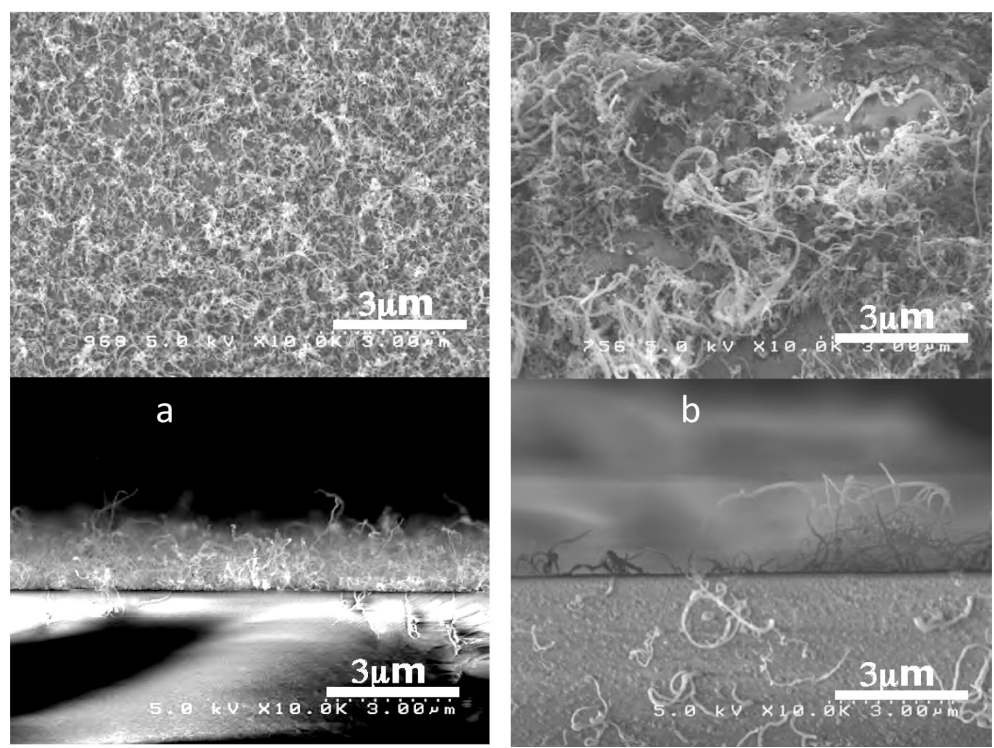

Figure 10. SEM observations of CNTs grown on (a) thin wet coated $0.01 \%$ $40 \mu$ l(iquid) $\mathrm{FeCl}_{2}$ and (b) $\mathrm{FeCl}_{2}$ powders (control experiment).

and suitable for mass production of CNTs.

\section{Acknowledgements}

Authors would like to thanks Prof. Yoshikazu Nakayama from Osaka University for discussion of the results.

\section{References}

[1] Iijima, S. (1991) Helical Microtubules of Graphitic Carbon. Nature, 354, 56-58. http://dx.doi.org/10.1038/354056a0

[2] Harris, P.J. (1999) Carbon Nanotubes and Related Structures. Cambridge Univertsity, Cambridge.

[3] Dresselhaus, M.S., Dresselhaus, G. and Saito, R. (1992) Carbon Fibers Based on $C_{60}$ and Their Symmetry. Physical Review B, 45, 6234. http://dx.doi.org/10.1103/PhysRevB.45.6234

[4] Mintmire, J.W., Dunlap, B.I. and White, C.T. (1992) Are Fullerene Tubules Metallic? Physical Review Letters, 68, 631. 
http://dx.doi.org/10.1103/PhysRevLett.68.631

[5] Hamada, N., Sawada, S. and Oshiyama, A. (1992) New One-Dimensional Conductors: Graphitic Microtubules. Physical Review Letters, 68, 1579. http://dx.doi.org/10.1103/PhysRevLett.68.1579

[6] Iijima, S. and Ichihashi, T. (1993) Single-Shell Carbon Nanotubes of 1-nm Diameter. Nature, 363, 603-605. http://dx.doi.org/10.1038/363603a0

[7] Ebbesen, T.W. and Ajayan, P.M. (1992) Large-Scale Synthesis of Carbon Nanotubes. Nature, 358, $220-222$. http://dx.doi.org/10.1038/358220a0

[8] Charlier, J.-C. and Iijima, S. (2001) Growth Mechanisms of Carbon Nanotubes. Topics in Applied Physics, 80, 55-81. http://dx.doi.org/10.1007/3-540-39947-X_4

[9] Gómez, J.A., Marquez, A., Pérez, A. and Duarte-Moller, A. (2012) Simple Method to Synthesize Functionalized Carbon Nanotubes Employing Cobalt Nitrate and Acetone by Using Spray Pyrolysis Deposition Technique. Advances in Materials Science and Engineering, Article ID: 258673.

[10] Krause, B., Ritschel, M., Täschner, Ch., Oswald, S., Gruner, W., Leonhardt, A. and Petschke, P. (2010) Comparison of Nanotubes Produced by Fixed Bed and Aerosol-CVD Methods and Their Electrical Percolation Behaviour in Melt Mixed Polyamide 6.6 Composites. Composites Science and Technology, 70, 151-160. http://dx.doi.org/10.1016/j.compscitech.2009.09.018

[11] Mayne, M., Grobert, N., Terrones, M., Kamalakaran, R., Ruhle, M., Kroto, H.W. and Walton, D.R.M. (2001) Pyrolytic Production of Aligned Carbon Nanotubes from Homogeneously Dispersed Benzene-Based Aerosols. Chemical Physics Letters, 338, 101-107.

[12] Barreiro, A., Kramberger, C., Rummeli, M.H., Gruneis, A., Grimma, D., Hampel, S., Gemming, T., Buechner, B., Bachtold, A. and Pichler, T. (2007) Control of the Single-Wall Carbon Nanotube Mean Diameter in Sulphur Promoted Aerosol-Assisted Chemical Vapour Deposition. Carbon, 45, 55-61. http://dx.doi.org/10.1016/j.carbon.2006.08.013

[13] Andrews, R., Jacques, D., Rao, A.M., Derbyshire, F., Qian, D., Fan, X., Dickey, E.C. and Chen J. (1999) Continuous Production of Aligned Carbon Nanotubes: A Step Closer to Commercial Production. Chemical Physics Letters, 303, 467-474.

[14] Albert, G., Nasibulin, Moisala, A., Jiang, H. and Kauppinen, E.I. (2006) Carbon Nanotube Synthesis from Alcohols by a Novel Aerosol Method. Journal of Nanoparticle Research, 8, 465-475.

[15] Bell, M.S., Teo, K.B.K. and Milne, W.I. (2007) Factors Determining Properties of Multi-Walled Carbon Nanotubes/ Fibres Deposited by PECVD. Journal of Physics D: Applied Physics, 40, 2285-2292.

[16] Caughman, J.B.O., Baylor, L.R., Guillorn, M.A., Merkulov, V.I., Lowndes, D.H. and Allard, L.F. (2003) Growth of Vertically Aligned Carbon Nanofibers by Low-Pressure Inductively Coupled Plasma-Enhanced Chemical Vapor Deposition. Applied Physics Letters, 83, 1207. http://dx.doi.org/10.1063/1.1597981

[17] Lee, T.Y., Han, J.H., Choi, S.H., Yoo, J.B., Park, C.Y., Jung, T., Yu, S., Yi, W.K., Han, I.T. and Kim, J.M. (2003) Epitaxial Diamond on a Si/CaF $/ \mathrm{Ir}_{2}$ Substrate. Diamond and Related Materials, 12, 1335-1339. http://dx.doi.org/10.1016/S0925-9635(03)00083-9

[18] Nolan, P.E., Lynch, D.C. and Cutler, A.H. (1998) Carbon Deposition and Hydrocarbon Formation on Group VIII Metal Catalysts. The Journal of Physical Chemistry B, 102, 4165-4175. http://dx.doi.org/10.1021/jp9809960

[19] Chhowalla, M., Teo, K.B.K., Ducati, C., Rupesinghe, N.L., Amaratunga, G.A.J., Ferrari, A.C., Roy, D., Robertson, J. and Milne, W.I. (2001) Growth Process Conditions of Vertically Aligned Carbon Nanotubes Using Plasma Enhanced Chemical Vapor Deposition. Journal of Applied Physics, 90, 5308. http://dx.doi.org/10.1063/1.1410322

[20] Woo, Y.S., Jeon, D.Y., Han, I.T., Lee, N.S., Jung, J.E. and Kim, J.M. (2002) In Situ Diagnosis of Chemical Species for the Growth of Carbon Nanotubes in Microwave Plasma-Enhanced Chemical Vapor Deposition. Diamond and Related Materials, 11, 59-66. http://dx.doi.org/10.1016/S0925-9635(01)00519-2

[21] Lim, S.H., Yoon, H.S., Moon, J.H., Park, K.C. and Jang, J. (2006) Optical Emission Spectroscopy Study for Optimization of Carbon Nanotubes Growth by a Triode Plasma Chemical Vapor Deposition. Applied Physics Letters, 88, Article ID: 033114. http://dx.doi.org/10.1063/1.2166690

[22] Delzeit, L., McAninch, I., Cruden, B.A., Hash, D., Chen, B., Han, J. and Meyyappan, M. (2002) Growth of Multiwall Carbon Nanotubes in an Inductively Coupled Plasma Reactor. Journal of Applied Physics, 91, 6027. http://dx.doi.org/10.1063/1.1465101

[23] Meyyappan, M. (2009) A Review of Plasma Enhanced Chemical Vapour Deposition of Carbon Nanotubes. Journal of Physics D: Applied Physics, 42, Article ID: 213001.

[24] Muller, Ch., Leonhardt, A., Kutz, M., Büchner, B. and Reuther, H. (2009) Growth Aspects of Iron-Filled Carbon Nanotubes Obtained by Catalytic Chemical Vapor Deposition of Ferrocene. The Journal of Physical Chemistry C, 113, 2736-2740. http://dx.doi.org/10.1021/jp8101207

[25] Wolny, F., Muhl, T., Weissker, U., Lipert, K., Schumann, J., Leonhardt, A. and Buchner, B. (2010) Iron Filled Carbon 
Nanotubes as Novel Monopole Like Sensors for Quantitative Magnetic Force Microscopy. Nanotechnology, 21.

[26] Nasibulin, A.G., Brown, D.P., Queipo, P., Gonzalez, D., Jiang, H., Anisimov, A.S. and Kauppinen, E.I. (2006) Effect of $\mathrm{CO}_{2}$ and $\mathrm{H}_{2} \mathrm{O}$ on the Synthesis of Single-Walled CNTs. Physica Status Solidi (b), 243, 3087-3090. http://dx.doi.org/10.1002/pssb.200669211

[27] Nagaraju, N., Fonseca, A., Konya, Z. and Nagy, J.B. (2002) Alumina and Silica Supported Metal Catalysts for the Production of Carbon Nanotubes. Journal of Molecular Catalysis A: Chemical, 181, 57-62. http://dx.doi.org/10.1016/S1381-1169(01)00375-2

[28] Seo, J.W., Hernadi, K., Miko, C. and Forro, L. (2004) Behaviour of Transition Metals Catalysts over Laser-Treated Vanadium Support Surfaces in the Decomposition of Acetylene. Applied Catalysis A: General, 260, 87-91. http://dx.doi.org/10.1016/j.apcata.2003.10.003

[29] Li, Y., Kim, W., Zhang, Y., Rolandi, M., Wang, D. and Dai, H. (2001) Growth of Single-Walled Carbon Nanotubes from Discrete Catalytic Nanoparticles of Various Sizes. The Journal of Physical Chemistry B, 105, 11424-11431. http://dx.doi.org/10.1021/jp012085b

[30] Huang, S., Woodson, M., Smalley, R. and Liu, J. (2004) Growth Mechanism of Oriented Long Single Walled Carbon Nanotubes Using “Fast-Heating” Chemical Vapor Deposition Process. Nano Letters, 4, 1025-1028. http://dx.doi.org/10.1021/nl049691d

[31] Laude, T., Kuwahara, H. and Sato, K. (2007) $\mathrm{FeCl}_{2}$-CVD Production of Carbon Fibres with Graphene Layers Nearly Perpendicular to Axis. Chemical Physics Letters, 434, 78-81. http://dx.doi.org/10.1016/j.cplett.2006.11.091 
Scientific Research Publishing (SCIRP) is one of the largest Open Access journal publishers. It is currently publishing more than 200 open access, online, peer-reviewed journals covering a wide range of academic disciplines. SCIRP serves the worldwide academic communities and contributes to the progress and application of science with its publication.

Other selected journals from SCIRP are listed as below. Submit your manuscript to us via either submit@scirp.org or Online Submission Portal.
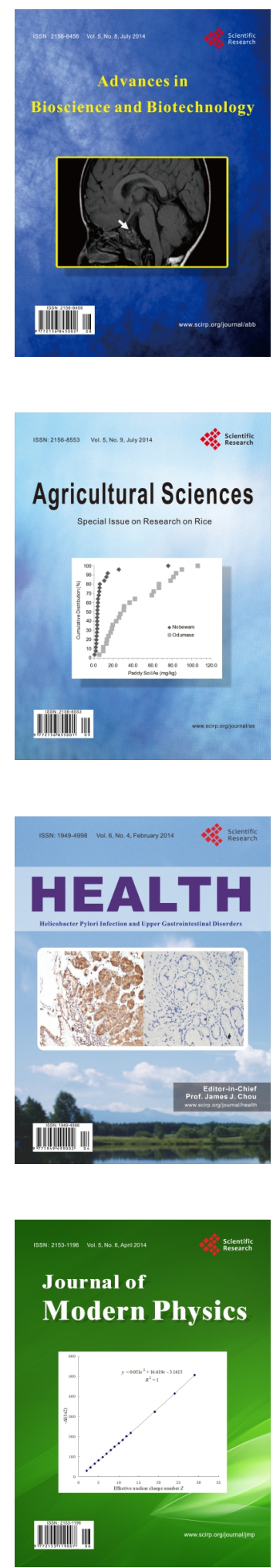
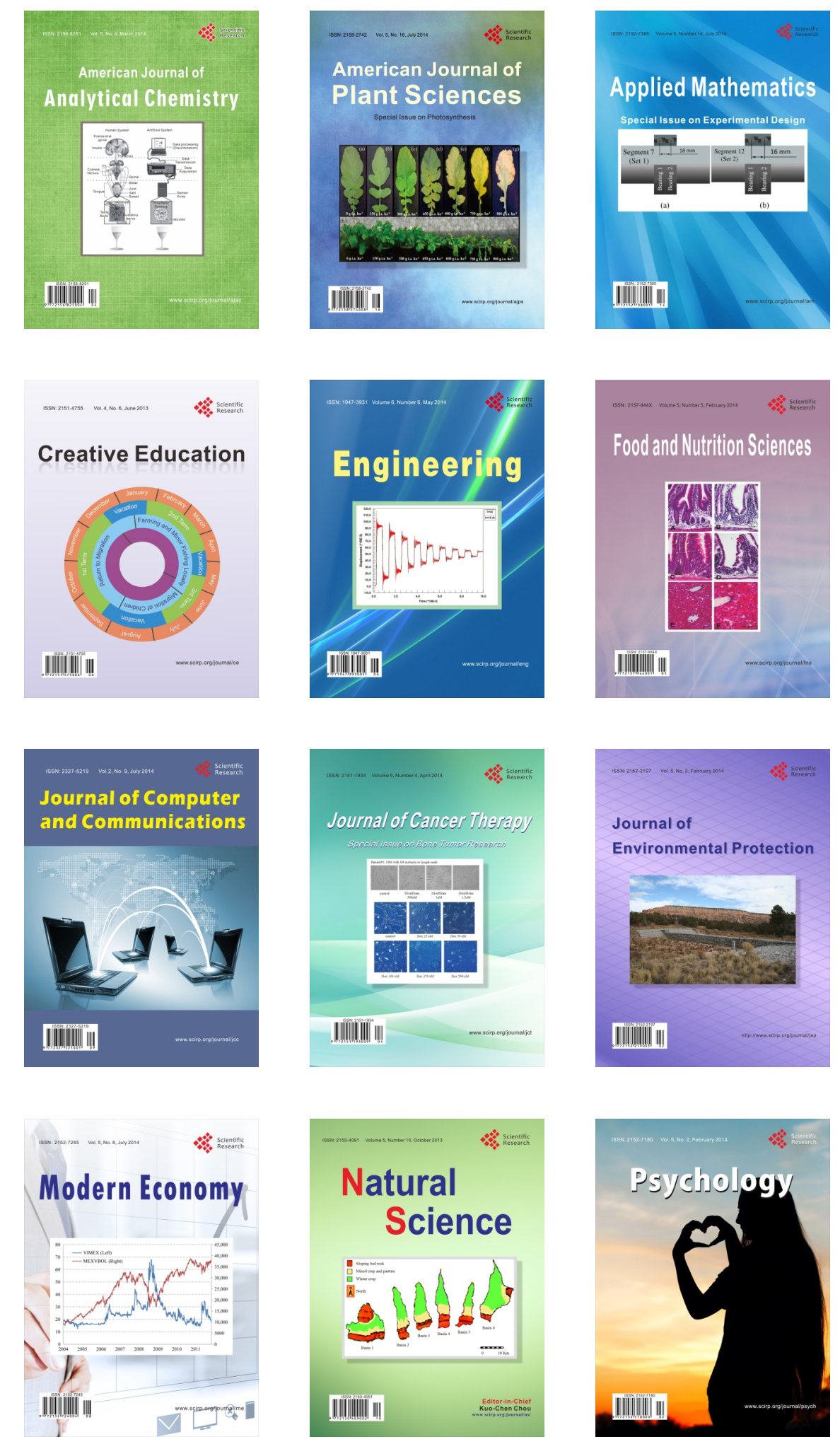